\title{
A Comparative Study of Clinical, Ultrasound and Aspiration Cytology Studies in Diagnosing Carcinoma of Thyroid
}

\author{
Nidhin Skariah ${ }^{1}$, Abdul Siyad AK ${ }^{2}$ \\ ${ }^{1}$ Resident, Department of Surgery, Government Medical College, Thrissur,Kerala, India. \\ ${ }^{2}$ Additional Professor, Department of Surgery, Government Medical College, Thrissur,Kerala, India.
}

\begin{abstract}
Background and Objectives: Although fine-needle aspiration cytology (FNAC) is considered to be the reference method for evaluating thyroid nodules, the results are often inaccurate in approximately 10-30\% of cases. In many cases the preoperative clinical evaluation (CE), FNAC and ultrasound (US) evaluation fail to diagnose a case of thyroid cancer and may require a second surgery for completion Thyroidectomy. This review aims to compare the clinical, ultrasound, and fine needle aspiration methods that can be used for thyroid nodule management.
\end{abstract}

Methods: All cases who were admitted in the department of general surgery with thyroid swellings planned for surgery over one and half years were studied and followed up. Patients who were detected to have malignancy histopathologically in the post operative specimen were assessed. The clinical, ultrasound and aspiration cytology studies of these patients were evaluated and compared.

Results and Discussion: Out of the 372 patients 113(30.38\%) were diagnosed as thyroid carcinoma histopathologically (p less than .001). Clinical evaluation (CE) detected $69(61.06 \%$ ) out of 113 patients. US detected 81(71.78\%) and FNAC studies detected 88(77.88\%).

Conclusion: Among the three methods FNAC detected the maximum number of carcinoma thyroid and proved to be most effective in preoperative diagnosis and the results of fine needle aspiration cytology cannot completely rule out the presence of malignancy in thyroid swellings.

Keywords : Ultrasonogram, Thyroid carcinoma, FNAC.

\section{Introduction}

Thyroid is unique that it is the largest endocrine gland, the only one which a clinician can examine directly. It is affected by a vast array of developmental, inflammatory, hyperplastic and neoplastic disorders. Only 1 in 29 clinically identifiable swellings is malignant. Only about $20 \%$ of patients undergoing surgery actually show histology of malignancy. Clinical examination may give information about the swelling which if solid there is $24 \%$ chance of malignancy and if cystic there is $12 \%$ chance of malignancy. Also painless, firm, mass with fixation to surrounding, hoarseness and ipsilateral nodal enlargement are signs of malignancy (1) Ultrasonogram (US) is a non-invasive supplement to clinical examination. Micro calcification, hypervascularity, infiltrative margins, being hypoechoic (no halo), solid swellings, taller than wide are signs of malignancy in US (2). FNAC has got excellent patient compliance and is quick to perform. It can differentiate between different thyroid malignancies except in follicular carcinoma. It is $86 \%$ sensitive and $91 \%$ specific (3). In many cases the preoperative clinical, FNAC and US evaluation fail to diagnose a case of papillary ca thyroid and may require a second surgery. This study aims to evaluate the diagnostic accuracy of the above three in carcinoma thyroid which helps in planning appropriate management.

Thyroid carcinoma in patients submitted to thyroidectomy for a benign thyroid disease is quite frequent $(4,5)$.The frequency of incidental papillary carcinoma has been reported to be between $4.6 \%$ and $10 \%$ in operatively treated benign thyroid diseases (6). Surgeons often encounter incidental carcinoma, despite the recent wide availability of US studies and fine-needle aspiration biopsy (7). Papillary carcinoma is the most common variety of incidental cancer found in multinodular goiter (8).Improved detection rates due to availability of US and FNAC studies may not represent the only cause of increased incidence of incidental thyroid cancer (10). The incidence of false-negative rate in FNAC is approximately 3\% and this rises up to $20 \%$ in cases where FNAC shows a suspicious cytology.

\section{Aims And Objectives}

- To pick up all cases of carcinoma of Thyroid diagnosed histologically after Thyroidectomy.

- To review the clinical, US and FNAC diagnosis in the above cases.

- To compare the proportion diagnosed as positive for cancer by clinical US and FNAC studies.

III. Materials and Methods 


\subsection{Source Of Data}

Patients who were diagnosed to having carcinoma of thyroid in the study period in Govt. Medical

College Thrissur.

\subsection{Method Of Collection Of Data}

Data was collected from history, appropriate physical examination radiological and histopathological investigations.

\subsection{Place Of Study}

Govt Medical College, Thrissur,Kerala,india.

3.4.Sample Size

The lower proportion among the three investigations to get the number of histopathology

positives included in the study was taken as sample size.

\subsection{Inclusion Criteria}

Patients presented with neck swelling and diagnosed as carcinoma of thyroid post operatively

by histopathology, who were willing to participate in study.

\subsection{Exclusion Criteria}

1. Patients finally diagnosed histopathologically as Follicular cancers.

2. Patients diagnosed to have benign thyroid diseases post operatively.

\subsection{Statistical Analysis}

This is a cross sectional study. Descriptive statistical principles were used such as rates, ratios, means and percentages, proportions etc.

\subsection{Methodology}

The study was conducted in Govt medical college, Thrissur, among patients who attended the outpatient/casualty department or admitted in wards of general surgery during the study period between January 2015 and December 2016 who underwent surgery for thyroid swelling were followed up. After getting informed consent from the patient, history was taken according to a pretested semistructured questionnaire provided, with routine clinical examination, followed by US and FNAC. Cases which finally turned out to be cancers of thyroid were selected. CE done previously and recorded were reviewed. The US done for the above patients were also reviewed and recorded. The rates of detection of thyroid cancer as per CE, US and FNAC were assessed and recorded.

CE with history of painless neck swelling, rapid increase in size, hoarseness, loss of weight /appetite, skull swellings and examination findings like Cervical lymph nodes, painless hard neck swelling moving up with deglutition, local fixity, Irregular margins, non palpable carotids, voice changes and ultrasound findings like Calcification, hypervascularity, infiltrative margins, hypoechoicity (no halo), more taller than wide were all considered as malignant lesions.

If majority of findings are suggestive of malignancy clinically or radiologically, they are taken as positive. Resulting data was analysed and compared to know the proportions.

Ethical concern-The study protocol was submitted to Ethics committee (IRC) of Govt medical college,Thrissur for approval and study was conducted after obtaining the approval. A written informed consent was taken from the participants.The information collected was used only for the purpose of study and strict confidentiality was maintained throughout study.

\section{Results}

4.1 Proportion of patients diagnosed as carcinoma of thyroid.

Table 1.

\begin{tabular}{|c|c|c|}
\hline Histopathology & Frequency & Percentage \\
\hline Positive & 113 & 30.38 \\
\hline Negative & 259 & 68.52 \\
\hline Total & 372 & 100 \\
\hline
\end{tabular}

Chart.1. 


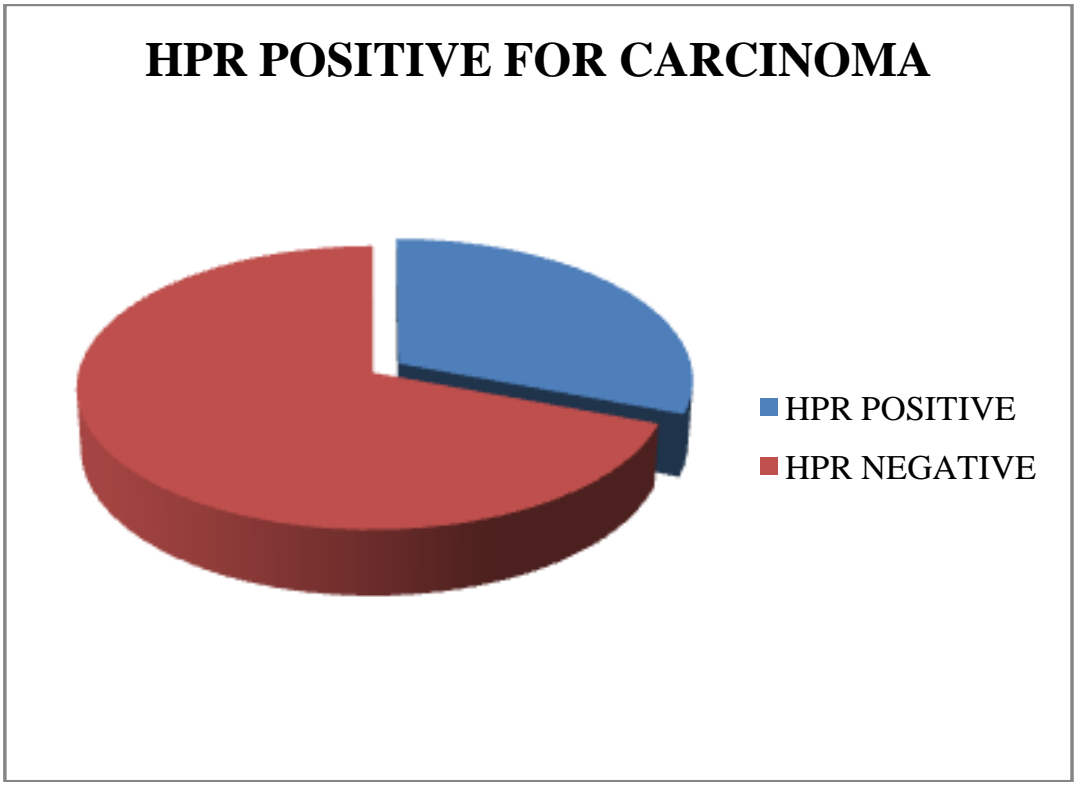

4.2.Proportion of histopathological types among patients included in study

Table.2.

\begin{tabular}{|l|l|l|}
\hline Histopathology & Frequency & Percentage \\
\hline Papillary Carcinoma & 103 & 91.15 \\
\hline Medullary Carcinoma & 6 & 5.31 \\
\hline Anaplastic Carcinoma & 4 & 3.54 \\
\hline Total & 113 & 100 \\
\hline
\end{tabular}

Chart.2.

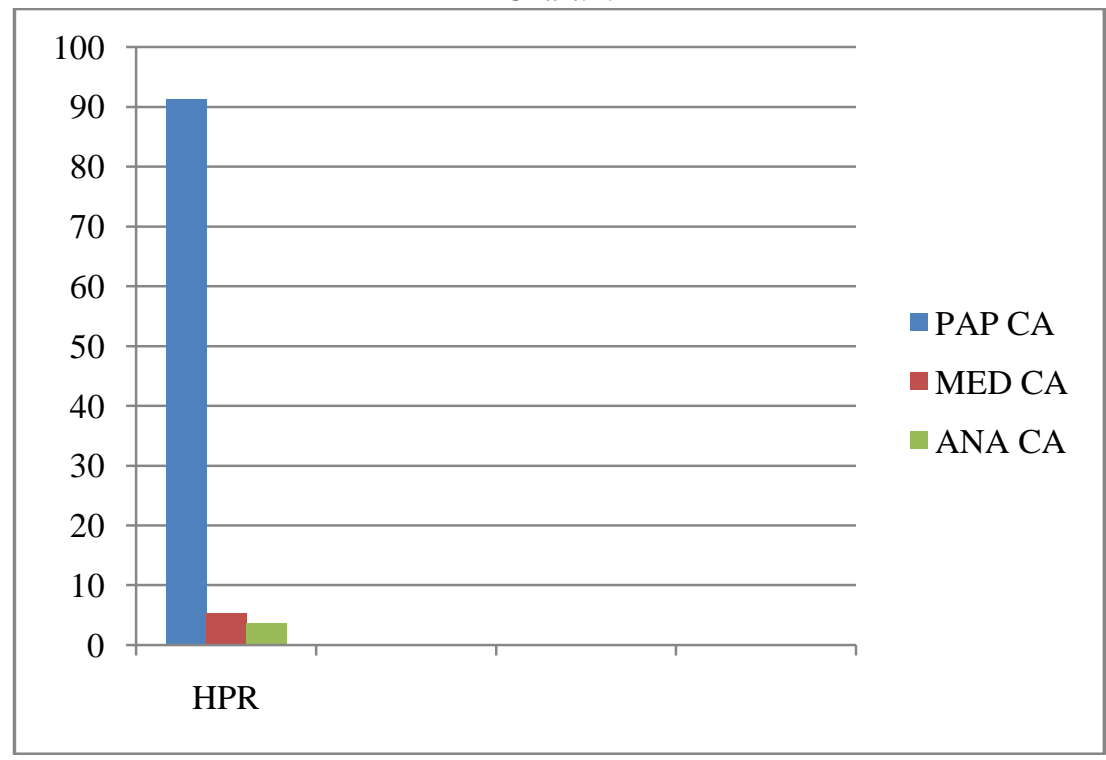

4.3.Proportion of patients with CE suggestive of carcinoma Thyroid.

Table 3.

\begin{tabular}{|c|c|c|}
\hline Examination & Frequency & Percentage \\
\hline Positive & 69 & 61.06 \\
\hline Negative & 44 & 38.94 \\
\hline Total & 113 & 100 \\
\hline
\end{tabular}

Chart 3. 


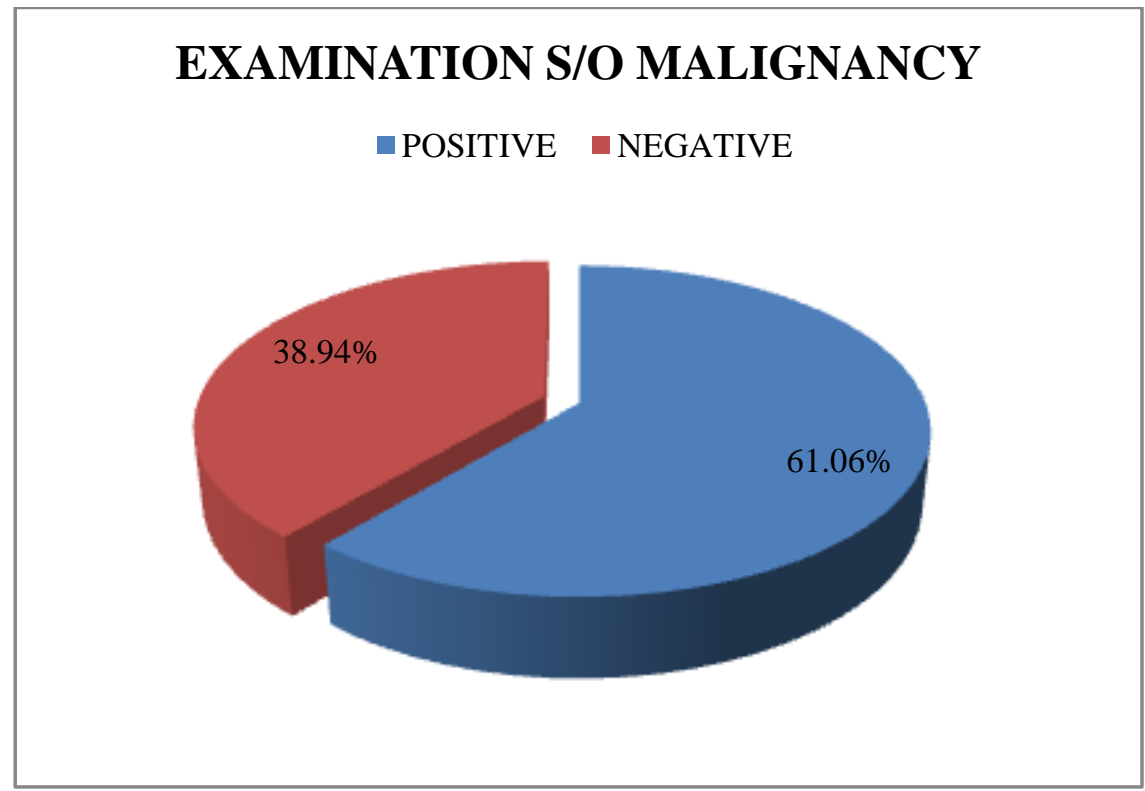

4.4. Proportion of patients with US suggestive of thyroid carcinoma

Table 4.

\begin{tabular}{|c|c|c|}
\hline Ultrasound & Frequency & Percentage \\
\hline Positive & 81 & 71.78 \\
\hline Negative & 32 & 28.32 \\
\hline Total & 113 & 100 \\
\hline
\end{tabular}

Chart 4.

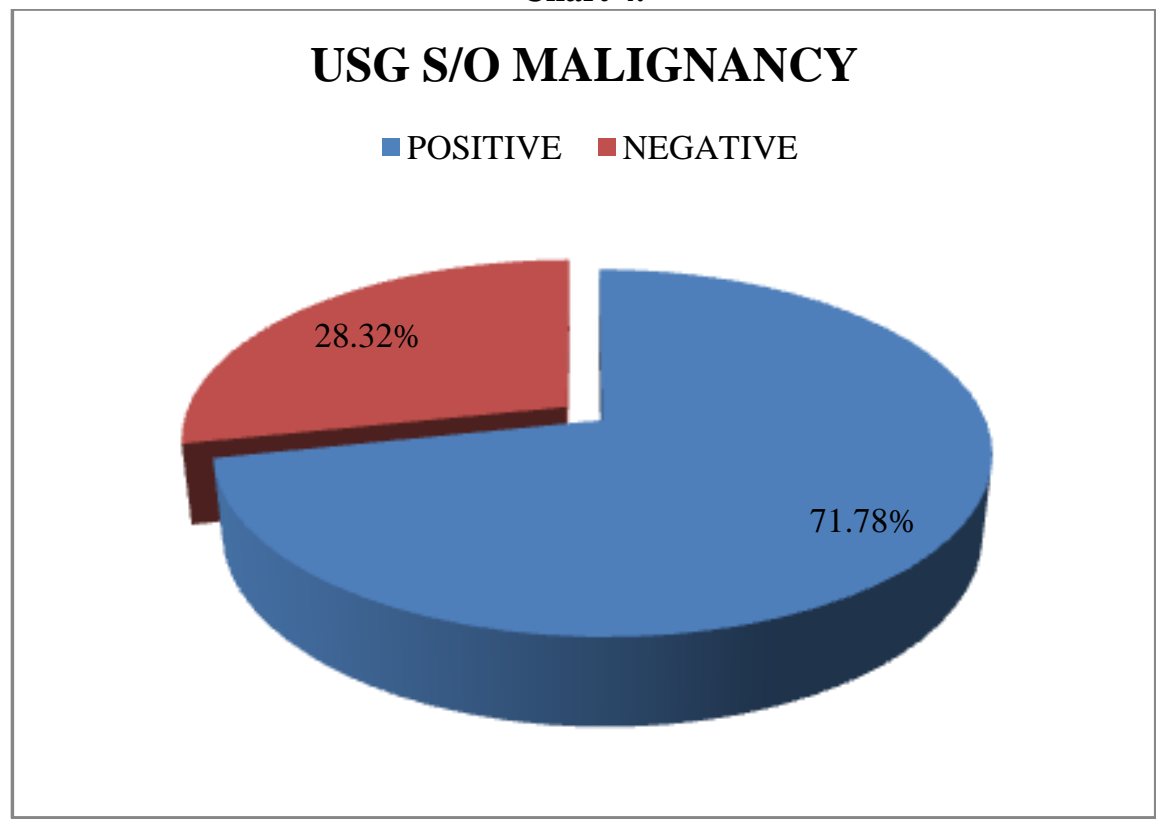

4.5. Proportion of patients with FNAC suggestive of thyroid carcinoma

Table 5.

\begin{tabular}{|l|l|l|}
\hline FNAC & Frequency & Percentage \\
\hline Positive & 88 & 77.88 \\
\hline Negative & 25 & 22.12 \\
\hline Total & 113 & 100 \\
\hline
\end{tabular}

Chart 5 . 


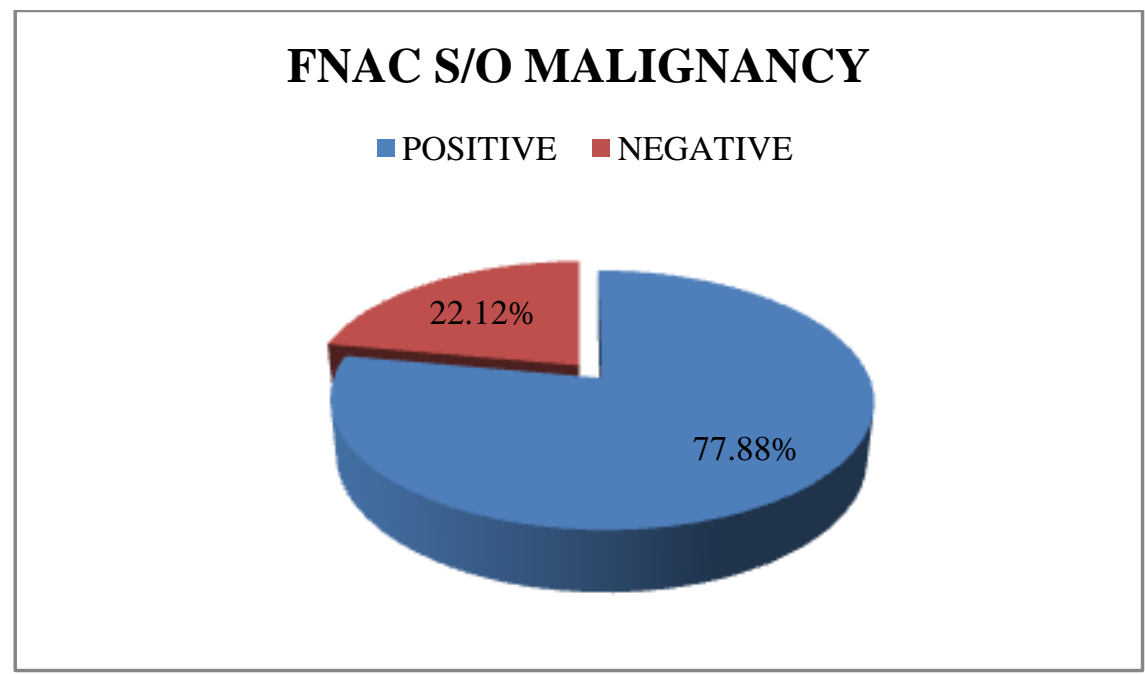

4.6. Comparison of proportions suggestive of malignancy with CE,US and FNAC among patients diagnosed as carcinoma thyroid

Table 6.

\begin{tabular}{|l|c|c|}
\hline Type Of Study & Frequency Found Positive & Percentage \\
\hline Clinical Evaluation & 69 & 61.06 \\
\hline Ultrasonogram & 81 & 71.78 \\
\hline FNAC & 88 & 77.88 \\
\hline
\end{tabular}

Chart 6.

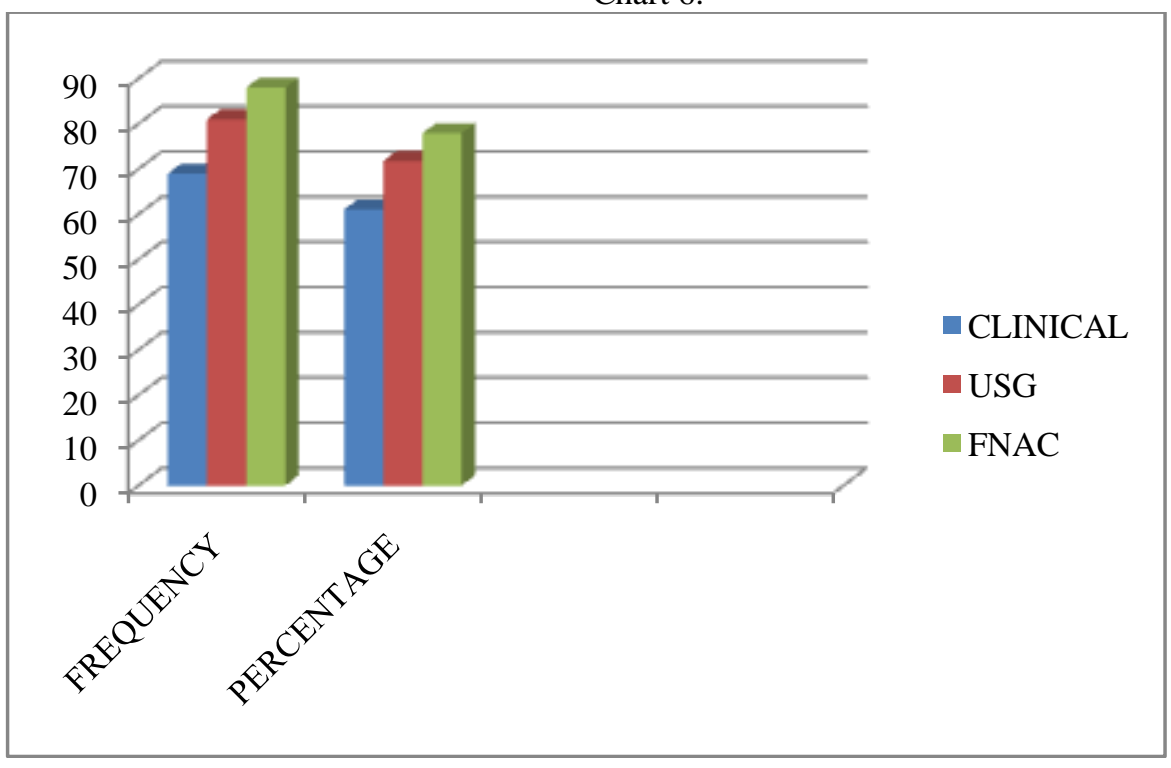

\section{DISCUSSION}

Thyroid cancer represents approximately $3 \%$ of all malignancies (11). Almost $75 \%$ of cases occur in women, making this the sixth most common malignancy in women. The most useful way of classifying Thyroid cancers is as follows(9).

\begin{tabular}{|c|c|c|c|}
\hline \multirow[t]{6}{*}{ Malignant } & \multirow[t]{4}{*}{ Primary } & $\begin{array}{l}\text { Follicular epithelium - } \\
\text { differentiated }\end{array}$ & $\begin{array}{l}\text { Follicular } \\
\text { Papillary }\end{array}$ \\
\hline & & $\begin{array}{l}\text { Follicular epithelium - } \\
\text { undifferentiated }\end{array}$ & Anaplastic \\
\hline & & Parafollicular cells & Medullary \\
\hline & & Lymphoid cells & Lymphoma \\
\hline & Secondary & Metastatic & \\
\hline & & Local infiltration & \\
\hline
\end{tabular}


Of thyroid cancers, 90 to $95 \%$ are categorized as well differentiated tumours arising from the follicular cells. Papillary, follicular, and Hürthle cell carcinomas are included in this category. Medullary thyroid cancer accounts for about $6 \%$ of thyroid cancers. Anaplastic carcinoma is an aggressive malignancy responsible for less than $1 \%$ of thyroid carcinomas. Of the 372 patients with thyroid swelling followed up in the study $113(30.38 \%)$ were diagnosed as thyroid carcinoma histopathologically (p less than .001)(Table1 Chart1).Of 113 patient who were diagnosed as thyroid carcinoma histopathologically,91(80.53\%)were females and 22(16.5\%) were males.84 (74.34\%) patients were below 50 years and 29(25.66\%) were above 50 years of age. Among sample population 103(91.15\%),6(5.31\%),4(3.54\%) proved to have Papillary carcinoma,Medullary carcinoma and Anaplastic carcinoma respectively by histopathology(Table2, Chart2). These observations were similar to standard literature. Clinical features suspicious for malignancy include painless and firm masses, fixation to surrounding structures, absent carotids, associated hoarseness, presence of ipsilateral adenopathy etc. On evaluation clinical examination detected $69(61.06 \%)$ out of 113 patients with carcinoma of thyroid(Table3,Chart3).

US is an important component of evaluation of thyroid disease. Ultrasound is increasingly being used to assist in FNA. Advantages of US include portability, cost effectiveness, and lack of ionizing radiation. The finding of a purely cystic lesion may be reassuring, but such lesions represent a small minority of thyroid nodules ( $1 \%$ to $5 \%$ ). Also, well differentiated thyroid cancers may have cystic components or be associated with cystic or solid nodules. Ultrasound findings in a nodule that are considered suspicious for malignancy include microcalcifications, hypervascularity, infiltrative margins, being hypoechoic compared with surrounding parenchyma, and having a shape that is taller than its width on transverse view(12). In our study Ultrasonogram of neck detected $81(71.78 \%$ ) out of 113 patients with carcinoma of thyroid(Table4, Chart4).

FNAC with a small-gauge needle (23 to 27 gauge) is a cost-effective and valuable tool and is now an accepted key modality for the evaluation of patients with thyroid nodules, FNAC was found to have a sensitivity of $86 \%$ and a specificity of $91 \%$.(13).For palpable nodules, FNAC may be performed without image guidance. Ultrasound guidance is recommended for non-palpable, posteriorly located, or cystic nodules and results in a lower rate of non-diagnostic cytology and sampling errors. The finding of a malignant diagnosis on FNAC is associated with a high rate of accuracy, approaching 100\%, and this finding should prompt resection.

In our study FNAC detected $88(77.88 \%$ ) out of 113 patients with carcinoma of thyroid (Table5, Chart5).Hence among the three methods FNAC detected the maximum number of carcinoma thyroid patients and proved to be the most effective in preoperative diagnosis of carcinoma of thyroid (Table6, Chart6). But the results of fine needle aspiration cytology cannot completely rule out the presence of malignancy in a thyroid swelling.

\section{Conclusions}

By this study we conclude that out of the three method used (CE,US and FNAC), FNAC is the most effective way of diagnosing Thyroid cancer even though FNAC cannot pick up all cases of Thyroid cancer.

\section{Abbreviations}

CE- Clinical evaluation, US- Ultrasonogram, FNAC- Fine needle aspiration cytology.

\section{References}

[1]. Sabiston textbook of surgery,19th edition,Elsevier publications, ch38, page 906

[2]. Frates MC, Benson CB, Charboneau JW, et al: Management of thyroid nodules detected at US: Society of Radiologists in Ultrasound consensus conference statement. Radiology 237:794-800,2005

[3]. Sabel MS, Staren ED, Gianakakis LM, et al: User of fine-needle aspiration biopsy and frozen section in the management of the solitary thyroid nodule. Surgery 122:1021-1026, 1997

[4]. Berker D, Isik S, Ozuguz U, Tutuncu YA, Kucukler K, Akbaba G et al. Prevalence of incidental thyroid cancer and its ultrasonographic features in subcentimeter thyroid nodules of patients with hyperthyroidism. Endocrine. 2011 Feb;39(1):13-20.

[5]. Pezzolla A, Lattarulo S, Milella M, Barile G, Pascazio B, Ciampolillo A, et al. Incidental carcinoma in thyroid pathology: our experience and review of the literature. Ann Ital Chir. 2010 May-Jun;81(3):165-9, Italian.

[6]. Bradly DP, Reddy V, Prinz RA, Gattuso P. Incidental papillary carcinoma in patients treated surgically for benign thyroid diseases. Surgery. 2009 Dec;146(6):1099-104.

[7]. Ito Y, Higashiyama T, Takamura Y, Miya A, Kobayashi K, Matsuzuka F et al. Prognosis of patients with benign thyroid diseases accompanied by incidental papillary carcinoma undetectable on preoperative imaging tests. World J Surg. 2007 Aug;31(8):1672-6.

[8]. Koh KB, Chang KW. Carcinoma in multinodular goiter. The Br J Surg. 1992 Mar;79(3):266-7

[9]. Norman S Williams, Christopher J.K. Bullstrode, Ronan O’Connell, editors. Bailey and Love's Short Practice of Surgery. 26 th Edition. CRC Press Private Ltd; 2013. p. 765.

[10]. Yoo F, Chaikhoutdinov I, Mitzner R, Liao J, Goldenberg D. Characteristics of Incidentally Discovered Thyroid Cancer. JAMA Otolaryngol - Head Neck Surg. 2013 Nov 1;139(11):1181-6

[11]. Siegel R, Ward E, Brawley O, et al: Cancer statistics, 2011. CA Cancer J Clin 61:212-236, 2011.

[12]. Frates MC, Benson CB, Charboneau JW, et al: Management of thyroid nodules detected at US: Society of Radiologists in Ultrasound consensus conference statement. Radiology 237:794-800, 2005.

[13]. Wada N, Duh QY, Sugino K, et al: Lymph node metastasis from 259 papillary thyroid microcarcinomas: Frequency, pattern of occurrence and recurrence, and optimal strategy for neck dissection. Ann Surg 237:399-407, 2003. 
Budget for the study: Expenses for the study was handled by the investigator. No other source of funds was available. There was economic burden on the patient.

Conflicts of interes

The authors declare that they have no conflicts of interest. 